Available online at www.easdprocedia.org

EASD Procedia EURODYN (2020) 1053-1062

EASD

Procedia
EURODYN 2020

XI International Conference on Structural Dynamics M. Papadrakakis, M. Fragiadakis, C. Papadimitriou (eds.) Athens, Greece, 23-26 November 2020

\title{
DAMAGE ANALYSIS OF STEEL-CONCRETE COMPOSITE BEAMS UNDER STATIC LOADS
}

\author{
Faraz Sadeghi ${ }^{1}$, Xinqun $\mathrm{Zhu}^{1}$, Jianchun $\mathrm{Li}^{1}$ \\ ${ }^{1}$ Centre for Built Infrastructure Research (CBIR), School of Civil and Environmental Engineering, \\ University of Technology Sydney (UTS), Sydney, NSW 2007, Australia
}

Faraz.Sadeghi@student.uts.edu.au

\{Xinqun.Zhu, Jianchun.Li\}@uts.edu.au

Keywords: Damage analysis, Parametric study, Composite structures, Steel-concrete composite beams, Static measurements

\begin{abstract}
This paper presents a study of the static behavior of steel-concrete composite beams with different types of damage. Since the behavior of a composite beam under load is governed by the shear connection, it is important to investigate the overall structural response due to different levels of damage in the interface and composite layers. A finite element (FE) model of a steel-concrete composite beam is developed based on two Euler-Bernoulli beams as the composite layers coupled with a deformable shear connection. Three different damage indices are defined for the concrete slab, the steel girder, and the distributed shear connection and then embedded into the stiffness matrix of the composite beam. This model is validated by comparing its load-displacement behavior with an equivalent FE model developed using the commercial FE software ABAQUS. The impact that the loading location has on the results is then investigated. A convergence study is also carried out in terms of the displacements and strains to determine the number of composite beam FEs. The maximum displacements and strains of composite beams with different types and levels of damage are then investigated. The numerical analysis showed that after an initial reduction when the number of FEs increase, the changes in displacement and strain at each location are very small. Moreover, the bonding slip has almost no effect on the measurements, and the changes in maximum displacement and strain from undamaged to maximum damage are almost the same.
\end{abstract}

ISSN:2311-9020 (C) 2020 The Authors. Published by EASD Procedia.

Peer-review under responsibility of the Organizing Committee of EURODYN 2020.

doi: $10.47964 / 1120.9085 .18540$ 


\section{INTRODUCTION}

Assessing structural damage through dynamic and static analysis has become increasingly popular because the dynamic and static response of a structure are functions of its physical parameters and therefore any changes in these parameters can be reflected in the structural responses. This is why attempts have been made to evaluate the structural integrity by developing approaches based on dynamic and static measured data. Although few studies can be found in static-based methods, dynamic-based methods have been studied more widely because they are easier to implement $[1,2]$. Static-based methods are based on equilibrium equations where the only significant parameter is the stiffness of a structure, which is why any reduction in stiffness due to damage is a significant parameter for damage analysis in terms of the static responses. A large number of measurements are needed to accurately analyse structural damage, which is not practical, however this problem can be solved by changing the loading locations and increasing the number of tests rather than the measurement sensors [3]. There are a number of researches into static-based methods which considered beam structures, and trusses or frames as case studies. For example, Liu and Chian [4] proposed a method to identify the elemental properties of a truss using strain values, Sanayei et al [5] used the deflection and strain data of a steel frame to estimate stiffness parameters, and Laory et al [6] used static measurements to determine the number of sensors. Wang et al [7] examined how partial shear interaction affected the static and dynamic response of steel-concrete composite structures, and found that bond slip and changes to the mode shapes are the effective parameters for identifying damage.

Different models have been developed to investigate the behaviour of steel-concrete composite structures, especially the effect of bond slip. Nie et al [8] studied the effects of bond slip on the deformation of steel-concrete composite beams using its equivalent rigidity, and found that bond slip is an effective contributor to beam deformation. Kumar et al [9] used push out test to determine how the thickness of the adhesive layer affects the capacity of composite connections. Chen et al [10] studied the static and fatigue behaviour of steel-concrete composite beams where the shear connectors had been corroded and found that the corroded studs had reduced the stiffness and load bearing capacity of the beams. Ayoub and Filippou [11] used an inelastic beam element to analyse a steel-concrete composite beam with partial interaction under cyclic loading and considered a shear connection with a distributed force as the interface model. Nguyen et al [12] used an FE model to carry out a linear static analysis of a steel-concrete composite beam with discrete shear bonding. Since no extreme loading conditions had been considered in most of the abovementioned studies, the displacements were very small and therefore the uplift effects were omitted, however, the bonding slip affects the behaviour of two-layer composite beams and must be included [12-14]. Whereas in static-based methods the displacements and/or strains are utilized to analyse structural damage, it is necessary to investigate how these parameters change in terms of different damage types.

In this paper we have developed a steel-concrete composite element with a bonding interface where the layers of concrete and steel are independently interpolated into a displacement based finite element (FE) formulation. Cases with different types of damage are introduced to describe the reduction in stiffness of a concrete slab, a steel girder, and the bonding interface. This model is verified by comparing it with the results obtained from a similar model built using the commercial FE software ABAQUS [15], where the optimal number of FEs are determined through a convergence study. A parametric study is also carried out using displacement and strain measurements. The effects that different levels of damage, and the measurements and loading locations have on the identified results are also discussed. 


\section{DISPLACEMENT BASED FINITE ELEMENT FORMULATION}

\subsection{Equilibrium and compatibility}

In this section a composite beam with two layers and a deformable shear connection is formulated such that the composite beam element consists of a concrete slab on top of a steel girder with bonding interfaces (Figure 1). The equilibrium equations for each layer are formulated by considering bond slip and the effects of uplift [16]. In Figure 1 the subscripts $c$ and $s$ denote the concrete and steel, $N, V, M$ and $h$ are the axial force, shear force, bending moment, and the distance between the interface and reference axes of each layer, respectively, and $D_{s c}$ and $D_{t}$ are the shear force (bonding slip) and transverse force (uplift) per unit length. An external distributed load $P$ is applied vertically to the concrete slab. The equilibrium equation for the composite beam section is introduced as [11]

$$
\partial^{T} \boldsymbol{F}(x)-\partial_{b}^{T} \boldsymbol{F}_{b}(x)-\boldsymbol{P}(\boldsymbol{x})=0
$$

where $\boldsymbol{F}(x), \boldsymbol{F}_{b}(x)$ and $\boldsymbol{P}(x)$ are the internal force vectors acting on the cross section, the interface bonding force, and the external load vector, respectively, and $\partial$ and $\partial_{b}$ are the differential operators. Although any section of this composite beam has four unknown forces $N_{c}, N_{S}, M$ and $D_{s c}$, there are only three equations of equilibrium for each section, so the compatibility equations should be merged to avoid any indeterminacy with the composite beam.

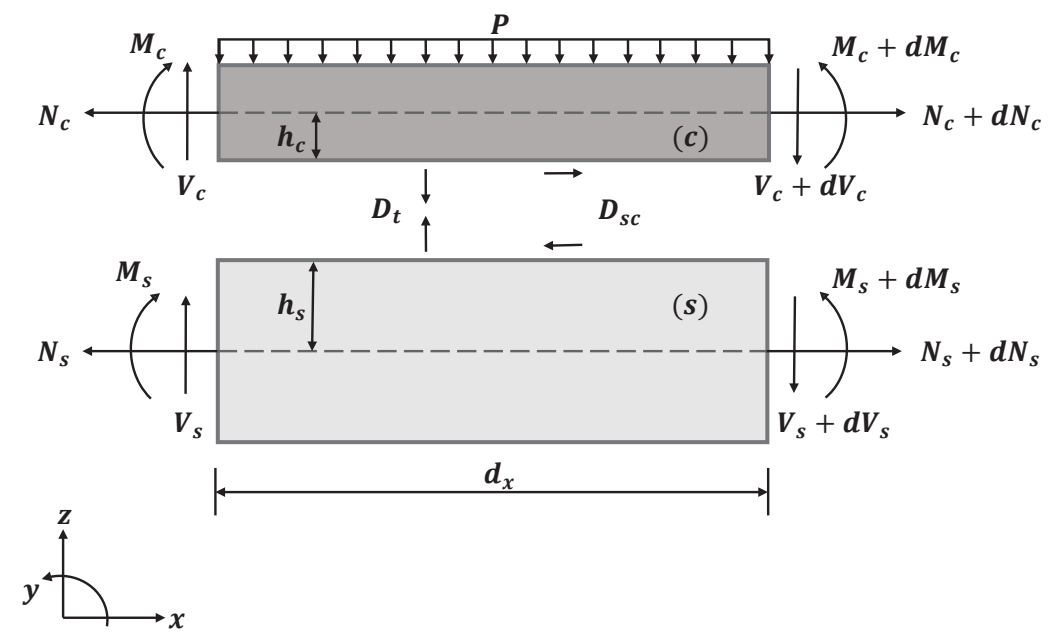

Figure 1: Diagram of a two layered composite beam element where (c) and (s) are the concrete slab and steel girder, respectively.

Since the same transverse displacement (no uplift) is considered for both layers of the composite beam, the curvature and rotation will be the same, even though different axial deformation can occur in the steel and concrete sections. The axial and transverse deformations of the composite beam are handled by the compatibility conditions based on Euler-Bernoulli beam theory. The compatibility conditions define deformation and displacement at the interface between the concrete slab and steel girder [11]. This relative displacement at the interface is known as the bond slip $g$ and can be defined as:

$$
g=u_{c}(x)-u_{s}(x)+h \partial_{x} v(x)
$$


where $u_{c}(x)$ and $u_{s}(x)$ are the axial displacements of the layers of concrete and steel, and $v(x)$ is the transverse displacement. The response of the composite beam subjected to external loads can be obtained with proper boundary conditions.

\subsection{Stiffness matrix}

The stiffness matrices for the concrete slab, steel girder, and bonding interface are used to define the local and global stiffness matrices of the composite beam element. A continuous spring element is considered as the interface element. The axial displacements of the composite beam are estimated using quadratic polynomial functions, while the transverse displacements are obtained by cubic Hermitian polynomials [17]. Two extra nodes have been added to the middle of the concrete slab and steel girder to provide a continuous bond slip condition along the interface. The vector of elemental nodal displacement is introduced as $\boldsymbol{U}=$ $\left[\begin{array}{llllllllll}u_{c 1} & u_{c 2} & u_{c 3} & u_{s 1} & u_{s 2} & u_{s 3} & v_{1} & \theta_{1} & v_{2} & \theta_{2}\end{array}\right]^{T}$ where each component represents a degree of freedom (DOF). The composite beam element with bond slip in the interface is handled by ten DOFs including a transverse and rotation in each node, and six axial displacements (Figure 2).

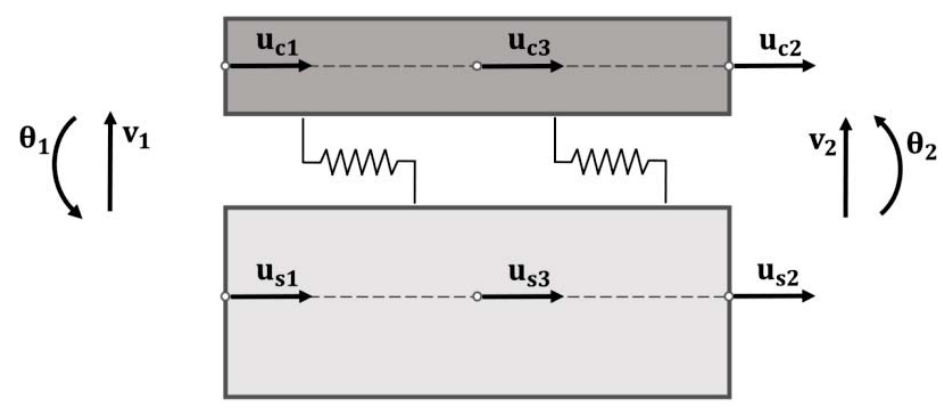

Figure 2: Nodal displacements of a steel-concrete composite element with 10 DOFs

To obtain the stiffness matrices, a small displacement due to an external load is presumed to occur and the amount of work is equal to the amount of residual internal strain energy. Therefore, the elemental stiffness matrices $\boldsymbol{k}_{e c}$ for the concrete, $\boldsymbol{k}_{e s}$ for the steel sections, and $\boldsymbol{k}_{e b}$ for the bonding interface are defined as:

$$
\boldsymbol{K}_{e}=\boldsymbol{K}_{e c}+\boldsymbol{K}_{e s}+\boldsymbol{K}_{e b}=\left[\begin{array}{lll}
{\left[\boldsymbol{K}_{e 1}\right]_{3 \times 3}} & {\left[\boldsymbol{K}_{e 2}\right]_{3 \times 3}} & {\left[\boldsymbol{K}_{e 3}\right]_{3 \times 4}} \\
{\left[\boldsymbol{K}_{e 4}\right]_{3 \times 3}} & {\left[\boldsymbol{K}_{e 5}\right]_{3 \times 3}} & {\left[\boldsymbol{K}_{e 6}\right]_{3 \times 4}} \\
{\left[\boldsymbol{K}_{e 7}\right]_{4 \times 3}} & {\left[\boldsymbol{K}_{e 8}\right]_{4 \times 3}} & {\left[\boldsymbol{K}_{e 9}\right]_{4 \times 4}}
\end{array}\right]_{10 \times 10}
$$

where $\boldsymbol{K}_{e}$ is the stiffness matrix for the steel-concrete composite element.

\subsection{Definition of damage}

A damage index is defined as the reduction in elemental stiffness of the composite beam layers where:

$$
\alpha=1-\frac{E}{\widehat{E}}
$$

where $\alpha$ is the damage index, and $E$ and $\widehat{E}$ are the equivalent Elastic modulus with and without damage, respectively. When damage index is zero, there is no damage in that element $(0 \ll$ $\alpha \ll 1)$. While the composite layers are assumed to be damaged, Eq (3) can be updated using the damage indicators as 


$$
\boldsymbol{K}_{e}=\boldsymbol{K}_{e c}+\boldsymbol{K}_{e s}+\boldsymbol{K}_{e b}=\left(1-\alpha_{c}\right) \widehat{\boldsymbol{K}}_{e c}+\left(1-\alpha_{s}\right) \widehat{\boldsymbol{K}}_{e s}+\left(1-\alpha_{b}\right) \widehat{\boldsymbol{K}}_{e b}
$$

where $\widehat{\boldsymbol{K}}_{e c}$ and $\widehat{\boldsymbol{K}}_{e s}$ are the stiffness matrices of the intact concrete and steel elements, and the subscripts $c, s$ and $b$ denote the damage indices for the concrete, steel, and bonding interfaces. These damage indices are considered individually as scalar values embedded in the elemental damage indices zero vectors with a size that is equal to the composite element FE numbers. A transformation matrix $\boldsymbol{T}$ is used to assemble the global stiffness matrix from the local stiffness matrix presented in $\mathrm{Eq}(5)$ as

$$
\begin{gathered}
\boldsymbol{K}=\boldsymbol{K}_{c}+\boldsymbol{K}_{s}+\boldsymbol{K}_{b}=\sum_{i=1}^{n} \boldsymbol{T}^{T} K_{e i} \boldsymbol{T} \\
=\sum_{i=1}^{n} \boldsymbol{T}^{T} \boldsymbol{K}_{e c i} \boldsymbol{T}+\sum_{i=1}^{n} \boldsymbol{T}^{T} \boldsymbol{K}_{e s i} \boldsymbol{T}+\sum_{i=1}^{n} T^{T} \boldsymbol{K}_{e b i} \boldsymbol{T} \\
=\sum_{i=1}^{n} \boldsymbol{T}^{T}\left(1-\alpha_{c i}\right) \widehat{\boldsymbol{K}}_{e c i} \boldsymbol{T}+\sum_{i=1}^{n} \boldsymbol{T}^{T}\left(1-\alpha_{s i}\right) \widehat{\boldsymbol{K}}_{e s i} \boldsymbol{T}+\sum_{i=1}^{\boldsymbol{T}^{T}}\left(1-\alpha_{b i}\right) \widehat{\boldsymbol{K}}_{e b i} \boldsymbol{T}
\end{gathered}
$$

where $n$ is the number of FEs. $\boldsymbol{K}, \boldsymbol{K}_{c}, \boldsymbol{K}_{s}$ and $\boldsymbol{K}_{b}$ are the global stiffness matrices of the damaged composite beam, concrete, steel and interface elements, and $\alpha_{c i}, \alpha_{s i}$ and $\alpha_{b i}$ are the $i$ th element damage indices of damaged concrete, steel and bonding interfaces, respectively.

\section{RESULTS AND DISCUSSION}

\subsection{Validation of the finite element model}

The structural model used in this study is a simply supported $6 \mathrm{~m}$ long steel-concrete composite beam with a concrete slab sitting on top of an I-shape steel girder with shear connectors. The Young's modulus and density of the concrete and steel are $E_{c}=3200 \mathrm{MPa}, \rho_{c}=$ $2700 \mathrm{~kg} / \mathrm{m}^{3}, E_{s}=210000 \mathrm{MPa}$ and $\rho_{s}=7800 \mathrm{~kg} / \mathrm{m}^{3}$, respectively. The geometrical characteristics of the beam are shown in Figure 3.

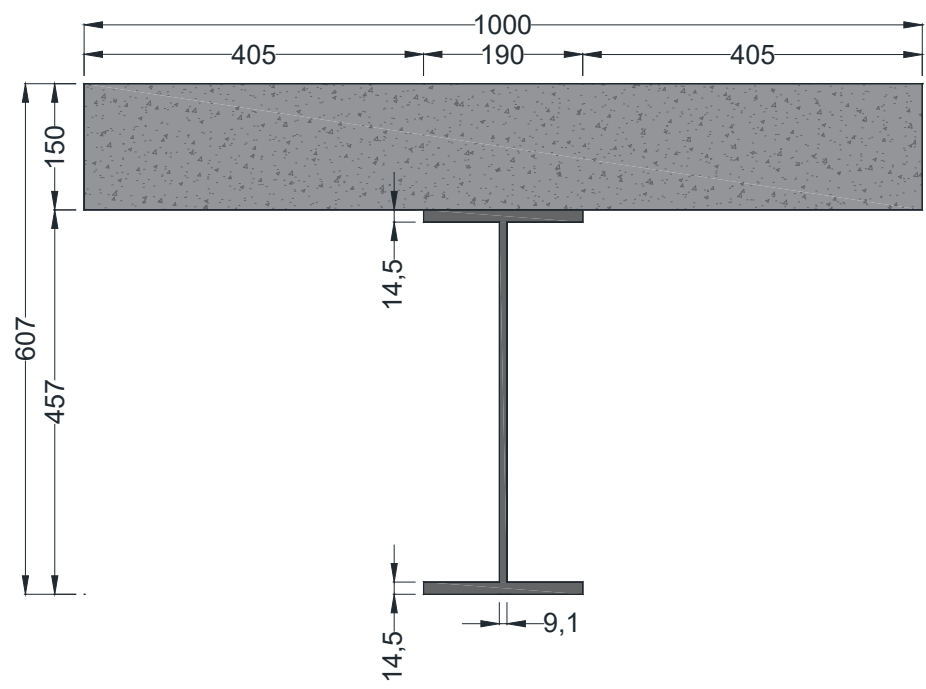

Figure 3: The geometrical characteristics of steel-concrete composite beam cross-section (length in $\mathrm{mm}$ ) 
To develop a reliable baseline FE model that could represent the real structure of interest, two equivalent FE models are constructed and their static response are compared. To this end an FE model of the steel-concrete composite beam is modelled by FE programming in MATLAB. This model is used for the damage identification in terms of different static loading locations, bond interactions, and damage cases. However, to obtain the baseline model, no damage and bond slip are considered in the analysis. Besides, another FE model with the same material and geometrical properties is built using the FE software ABAQUS, as shown in Figure 4.

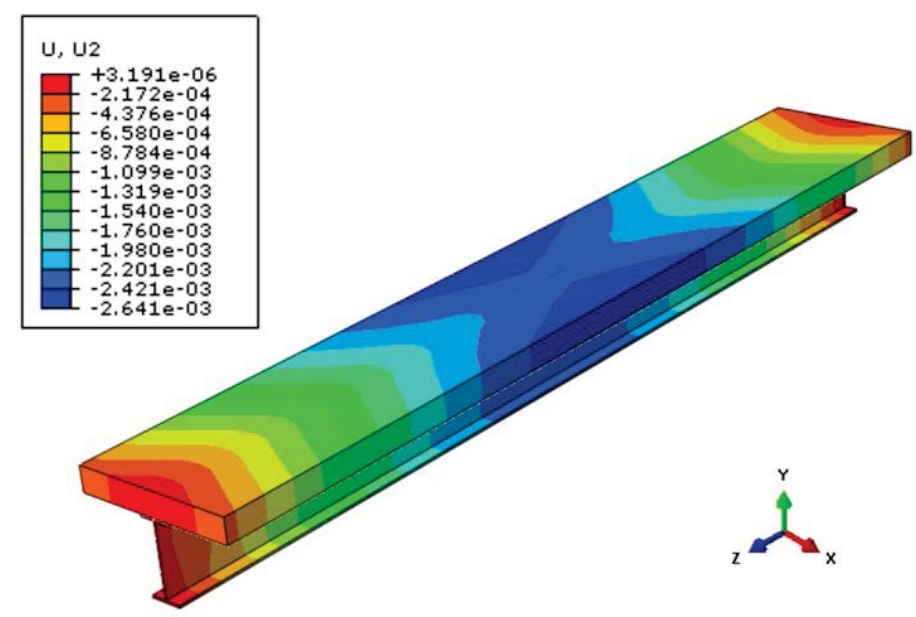

Figure 4: The FE model of steel-concrete composite beam showing displacements along the beam subjected to mid-span point loads

In each case the structure is subjected to a static load where $P=10000 \mathrm{~N}$ at the middle of the beam, and then at $L / 3$ from the left support; the analytical displacements are measured from 60 points located equally along the composite beam. The validity of this analysis is enhanced by analysing five models with 12, 24, 36, 48 and $60 \mathrm{FEs}$ for each case and then the displacements due to static loadings are used to compare the two FE models. Table 1 shows the maximum displacements of the steel-concrete composite beam obtained from the FE models developed in MATLAB (FE-M) and ABAQUS (FE-A). These displacements are almost the same for both models, showing how precise the FE model developed is by being programmed in MATLAB.

\begin{tabular}{lcccccc}
\hline Measurement & & \multicolumn{5}{c}{ Maximum Displacements } \\
\hline Number of FEs & & 12 & 24 & 36 & 48 & 60 \\
\hline \multirow{2}{*}{ Load applied at L/2 } & FE-M & $2.89 \times 10^{-3}$ & $2.64 \times 10^{-3}$ & $2.60 \times 10^{-3}$ & $2.58 \times 10^{-3}$ & $2.57 \times 10^{-3}$ \\
& FE-A & $2.65 \times 10^{-3}$ & $2.64 \times 10^{-3}$ & $2.63 \times 10^{-3}$ & $2.62 \times 10^{-3}$ & $2.61 \times 10^{-3}$ \\
\hline \multirow{2}{*}{ Load applied at L/3 } & FE-M & $2.46 \times 10^{-3}$ & $2.27 \times 10^{-3}$ & $2.23 \times 10^{-3}$ & $2.22 \times 10^{-3}$ & $2.21 \times 10^{-3}$ \\
& FE-A & $2.45 \times 10^{-3}$ & $2.26 \times 10^{-3}$ & $2.24 \times 10^{-3}$ & $2.21 \times 10^{-3}$ & $2.21 \times 10^{-3}$ \\
\hline
\end{tabular}

Table 1: Maximum displacements (in $\mathrm{m}$ ) measured from the numerical models in MATLAB (FE-M) and ABAQUS (FE-A)

The differences between the maximum displacements for the model with 12 FEs are greater than those with smaller sized mesh. A convergence study has been carried out using the FE-M in terms of different numbers of FEs, where the FEs are changed from 6 to 60 and the displacement and strain values are measured. 

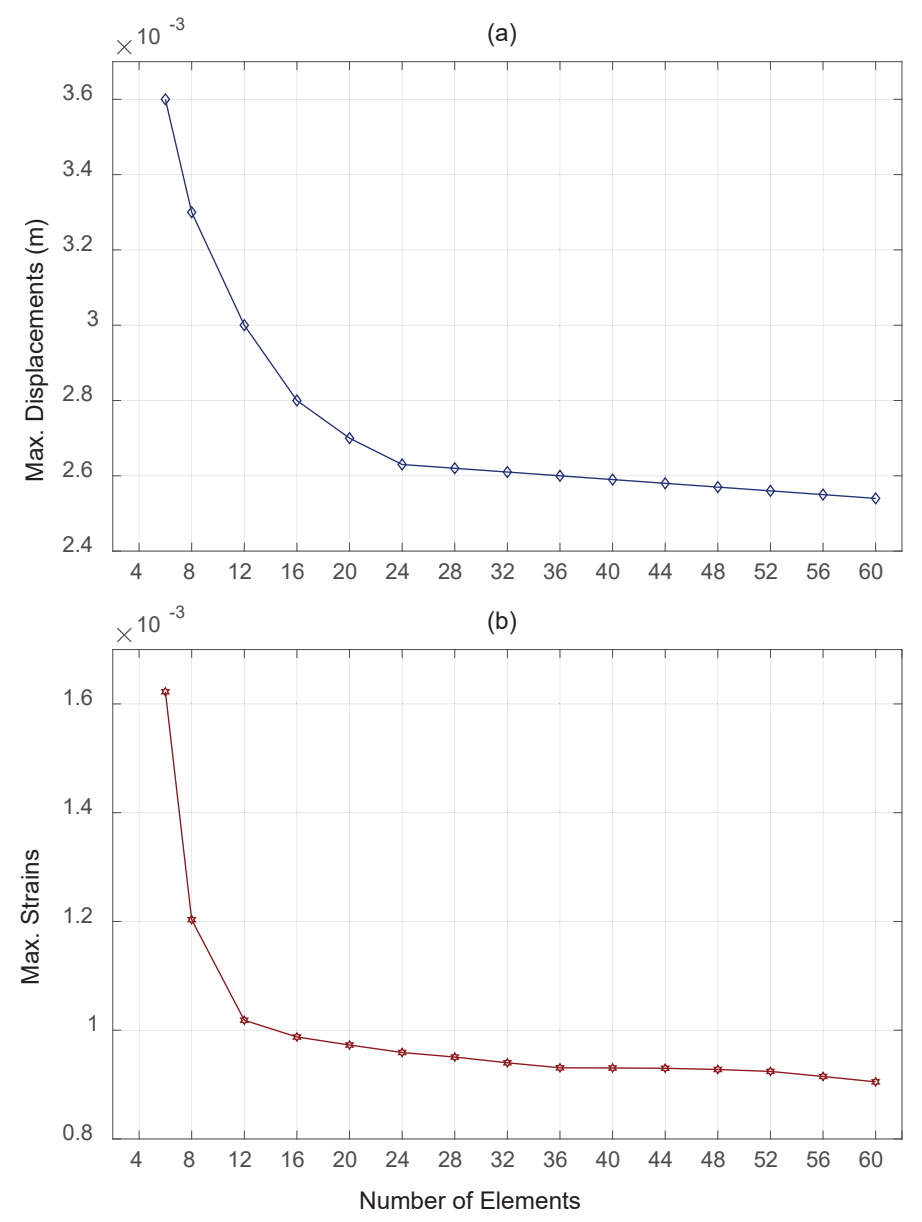

Figure 5: Convergence of maximum (a) displacement, and (b) strain in terms of the number of FEs

Figure 5 shows the convergence of maximum displacement and strain in terms of the number of FEs. While these maximum displacements and strains gradually improve by increments with the number of FEs, in both cases there is an immediate reduction in the models with FE numbers from 6 to 20. Furthermore, since the discrepancies of the model with 24 FEs are very small, 24 elements are used in the following studies.

\subsection{Parametric study}

A series of parametric studies based on the static responses of the beam have been carried out, and the behavior of the composite beam has been investigated for potential damages in terms of variations in static parameters such as displacement and strain. The parameter that best identifies damage is then selected. The parametric analysis is based on the displacements and strains of the composite beam for six different cases. This consists of three cases of single damage in concrete, steel and interface, two cases of double damage in the concrete-interface, and steel-interface, and one case of triple damage in the concrete-steel-interface. These cases are introduced as a reduction in the stiffness of an element in the composite beam.

Figure 6 shows the changes of maximum displacement and strain of the composite beam with 24 FEs in terms of different cases of damage and reductions in stiffness. Elements number 4 from the support on the left hand side of the composite beam have been considered as the damaged ones and a range of reduction in stiffness is applied from $0 \%$ to $90 \%$. The static responses of the composite beam have been obtained for six different cases of damage in ten steps 
of the stiffness reductions (intact to maximum damage). Although the maximum displacements increase when the stiffness decrease, these values are very small, particularly in the case of bonding loss. The discrepancies in the strains are almost zero for cases with a loss of bonding. Since the main objective is to analyse the damage on the bonding interface, the case with a single damage on the interface (Case 3 in Figure 6) is used to select the proper parameter. It is found that the loss of bonding interface results a minimum change in the maximum displacement (Figure 6.a) and strain (Figure 6.b) from undamaged to maximum damaged states. Therefore, in order to a reliable damage identification, both parameters could be used because their changes are almost the same.
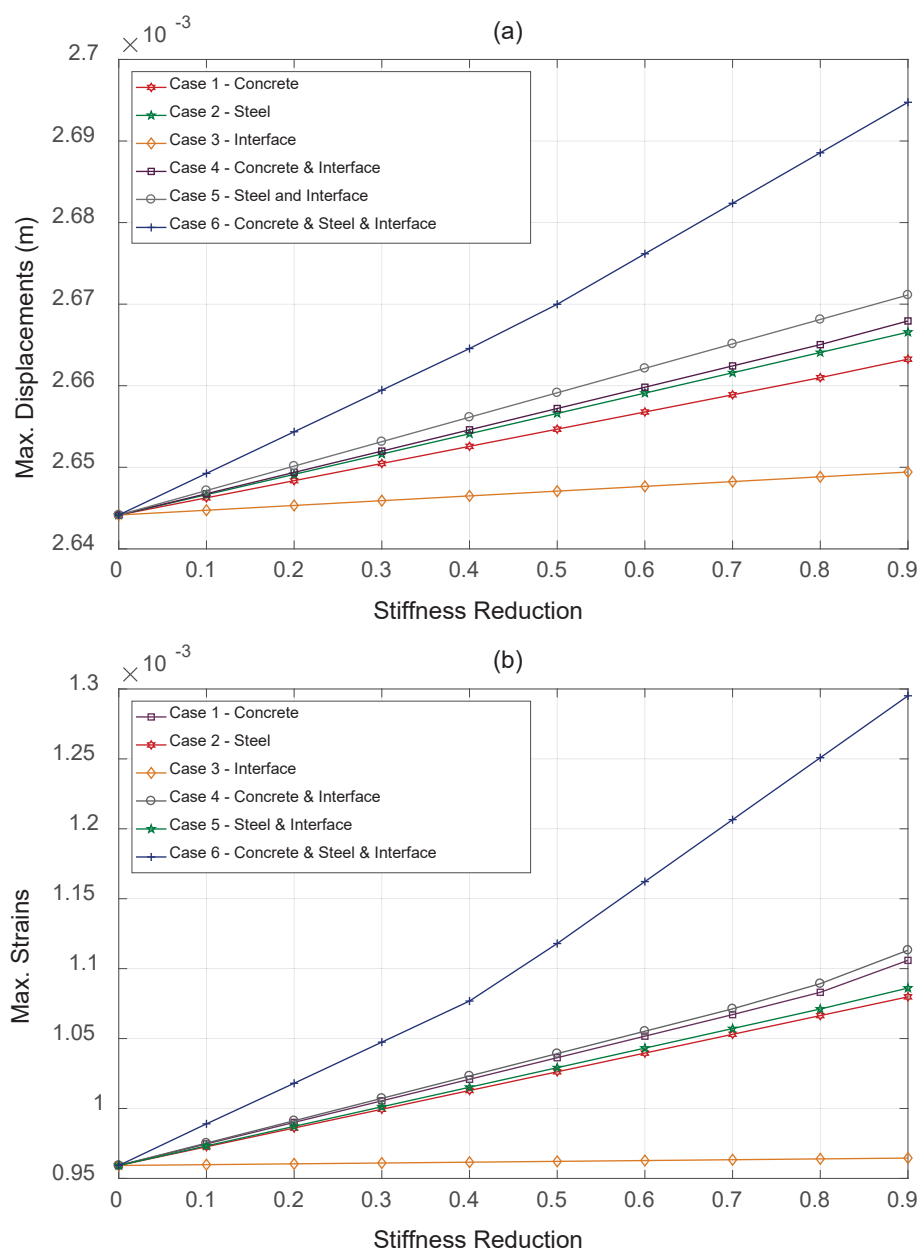

Figure 6: The changes of maximum (a) displacements and (b) strains of the beam with 24 FEs due to reductions in stiffness (from 0\% to 90\%) in Elements 4 for single damage (cases 1, 2 and 3), double damage (cases 4 and 5), and triple damage (case 6)

\section{REVIEW}

Peer review under the responsibility of the Scientific committee of Eurodyn 2020.

\section{CONCLUSION}

In this paper, a numerical analysis of various cases of structural damage has been carried out on a steel-concrete composite beam subjected to static loadings. An FE model of the composite beam is developed by incorporating a distributed shear connection, and then different damage 
indices have been embedded into the stiffness matrix of the beam. The results indicate that the model is reliable because the displacements are acceptable in terms of different load locations with a similar FE model built from the commercial FE package ABAQUS. The convergence study established to determine the optimal number of FEs for the composite beam indicates that the discrepancies in the displacements and strains after the model with 24 FEs are very small, and therefore 24 elements are used in the numerical analysis. The maximum displacements and strains in the beam in various cases are also investigated and compared. It is found that the maximum displacements and strains at each loading location remain constant after an initial reduction when the number of FEs increase. Moreover, the bonding slip does not impact the measurements very much, and the change of maximum displacements and strains from undamaged to maximum damage are almost the same.

\section{REFERENCES}

[1] Farrar CR, Doebling SW, Nix DA, Vibration-based structural damage identification, Philosophical Transactions of the Royal Society of London A: Mathematical, Physical and Engineering Sciences, 359:131-49, 2001.

[2] Fan W, Qiao P, Vibration-based damage identification methods: a review and comparative study, Structural Health Monitoring, 10:83-111, 2011.

[3] Choi I-Y, Lee JS, Choi E, Cho H-N, Development of elastic damage load theorem for damage detection in a statically determinate beam, Computers \& Structures, 82:2483-92, 2004.

[4] Liu P-L, Chian C-C, Parametric identification of truss structures using static strains, Journal of structural Engineering, 123:927-33, 1997.

[5] Sanayei M, Imbaro GR, McClain JA, Brown LC, Structural model updating using experimental static measurements, Journal of structural engineering, 123:792-8, 1997.

[6] Laory I, Hadj Ali NB, Trinh TN, Smith IF, Measurement system configuration for damage identification of continuously monitored structures, Journal of Bridge Engineering, 17:857-66, 2012.

[7] Wang Y, Hao H, Damage identification of slab-girder structures: experimental studies, $J$ Civ Struct Health Monit, 3:93-103, 2013.

[8] Nie J, Cai CS. Steel-concrete composite beams considering shear slip effects, Journal of Structural Engineering, 129:495-506, 2003.

[9] Kumar P, Patnaik A, Chaudhary S, Effect of bond layer thickness on behaviour of steelconcrete composite connections, Engineering Structures, 177:268-82, 2018.

[10] Chen J, Zhang H, Yu Q-Q, Static and fatigue behavior of steel-concrete composite beams with corroded studs, Journal of Constructional Steel Research, 156:18-27, 2019.

[11] Ayoub A, Filippou FC, Mixed formulation of nonlinear steel-concrete composite beam element, Journal of Structural Engineering, 126:371-81, 2000.

[12] Nguyen Q-H, Hjiaj M, Guezouli S, Exact finite element model for shear-deformable two-layer beams with discrete shear connection, Finite Elements in Analysis and Design, 47:718-27, 2011. 
[13] Henderson I, Zhu X, Uy B, Mirza O, Dynamic behaviour of steel-concrete composite beams retrofitted with various bolted shear connectors, Engineering Structures, 131:115$35,2017$.

[14] Henderson IEJ, Zhu XQ, Uy B, Mirza O, Dynamic behaviour of steel-concrete composite beams with different types of shear connectors, Part I: Experimental study, Engineering Structures, 103:298-307, 2015.

[15] ABAQUS. Online documentation help, theory manual: Dassault Systems. V. 6.14 edAccessed on; 2016.

[16] Adekola A, Partial interaction between elastically connected elements of a composite beam, International Journal of Solids and Structures, 4:1125-35, 1968.

[17] Amadio C, Fragiacomo M, A finite element model for the study of creep and shrinkage effects in composite beams with deformable shear connections, Costruzioni Metalliche, 4:213-28, 1993. 